\title{
Violence and its injury consequences in American movies: a public health perspective
}

\author{
David McArthur, Corinne Peek-Asa, Theresa Webb, Kevin Fisher, Bernard Cook, \\ Nick Browne, Jess Kraus
}

Southern California Injury Prevention Research Center, UCLA School of Public Health

D McArthur

C Peek-Asa

J Kraus

UCLA School of Film and Television

$\mathrm{T}$ Webb

K Fisher

B Cook

N Browne

Correspondence and reprint requests to: $\mathrm{Dr} \mathrm{D} \mathrm{L}$

McArthur, SCIPRC, CHS

76-078, UCLA School of

Public Health, Box 951772,

Los Angeles, CA

90095-1772, USA

(e-mail: dmca@ucla.edu)

\begin{abstract}
Objectives-The purpose of this study was to evaluate the seriousness and frequency of violence and the degree of associated injury depicted in the 100 top grossing American films of 1994.

Methods-Each scene in each film was examined for the presentation of violent actions upon persons and coded by means of a systematic context sensitive analytic scheme. Specific degrees of violence and indices of injury severity were abstracted. Only actually depicted, not implied, actions were coded, although both explicit and implied consequences were examined.

Results-The median number of violent actions per film was 16 , with a range from 1 to 110 . Intentional violence outnumbered unintentional violence by a factor of 10. Almost $90 \%$ of violent actions showed no consequences to the recipient's body, although more than $80 \%$ of the violent actions were executed with lethal or moderate force. Fewer than $1 \%$ of violent actions were accompanied by injuries that were then medically attended.

Conclusions-Violent force in American films of 1994 was overwhelmingly intentional and in four of five cases was executed at levels likely to cause significant bodily injury. Not only action films but movies of all genres contained scenes in which the intensity of the action was not matched by correspondingly severe injury consequences. Many American films, regardless of genre, tend to minimize the consequences of violence to human beings.

(Injury Prevention 2000;6:120-124)
\end{abstract}

Keywords: violence; film; media

Violence in popular entertainment media has recently moved onto the public health agenda as the causes, consequences, and prevention of violence have become the subject of urgent social debate. These concerns extend to scenes on television and in the movies in which the injury consequences to the victims of violence appear to be minimal, violence appears to be justified, and violent actions go unpunished. ${ }^{1}$ Both extensive research and policy discussions about media violence have indicated that, across widely differing forms of programming, television frequently depicts violent actions. ${ }^{2-4}$ Yet while research in media violence has a long history, popular American films shown in theaters seldom have been studied empirically.
The American film industry relies heavily on conventionalized patterns of cinematic treatment called "genres". Leading American films are distributed across 11 distinct genres: action, adventure, animation, comedy, drama, family, horror, romance, science fiction, thriller, and western. ${ }^{5}$ In 1994 just 100 of these films accounted for $89 \%$ of the domestic box office receipts of 4.5 billion US dollars (a figure that does not include revenues from video, cable, and international markets). Violence has long been basic to the definition of the action and western genres, but other genres such as comedy and drama have also increased the amount and severity of violence depicted. Depictions of violence, therefore, are seen by millions of US customers in theatrical release, and by additional millions in their international versions, on videotape, and in television reruns.

To offer a perspective on violence in contemporary American movies, this paper evaluates the occurrence of violent actions and their consequent injuries as they appear in film. The primary goal is to provide an account of the range and intensity of violent actions, and the depiction of injuries resulting from these actions.

\section{Methods}

The study sample included all 100 of the top grossing films released in 1994, identified in The Hollywood Reporter's annual summary of American films. ${ }^{5}$ (The year 1994 was chosen for convenience, not because of any prior expectation about levels of violence in that year's films. Titles are listed in Appendix A.) A computer driven abstraction instrument was used to control the playing of the laser disc edition of each film, and to encode the violence contained within each scene. Coders were three advanced graduate students in film and television. After each violent scene, the film was halted and questions regarding that scene were displayed in sequence on the screen. The coding used a hierarchical structure that allowed progressive movement from scenes to actions to injury consequences as a direct function of time. After coders entered their responses, the film progressed ahead. Data were recorded using an Apple PowerMac 7500 coupled with a Media Max video controller, and managed by Filemaker Pro and Paradox. Coders achieved an inter-rater agreement on all variables of $90 \%$.

The scene is the largest unit of dramatic action in a film, and defines the context in which violent actions occur within a given time and space. For this study a violent action within a single scene was defined as the fundamental unit of analysis, and included at minimum a 
single movement made by an initiator of a given action towards one or more recipients, for example, a punch thrown or a weapon discharged. Scenes with implicit rather than demonstrable violence (for example, threats, conspiratorial behavior, or conniving) were not included. A continuous series of the same explicit violent actions by the same character was treated as one if of equal severity and involving no new weapon. A change in severity of violence (for example, from mild to lethal) or method (for example, from fists to machete) resulted in coding a new action. The action's initiator, the recipient of violence, and the nature of the intention (for example, to kill, disable, dominate, capture, defend) were identified. Violence towards property rather than people was not analyzed for this paper.

The seriousness of each action was rated as minimal force (for example, pushing, slapping, chases not involving weapons, dousing with non-lethal substances), moderate force (hitting with a closed fist or with a weapon but without sufficient force to be life threatening), or lethal force (deadly or potentially deadly violence, generally though not always accomplished with a weapon). The explicitness of the portrayal was rated as none (only antecedents or aftermaths were shown, it occurred off screen, or there was no wounding or expression of force), minimal (little specific attention was given to the action or the wounding itself), moderate (the act included its culmination upon the victim, generally an injury or an apparent halt to that character's activity but the injury itself was not explicit), or full (the entire arc of violence from beginning to end was the subject of the filmmaker's attention during the scene, with graphic representation of victims' injuries). For each violent action, the presence of consequences in the form of depicted bodily injury and/or medical attention was evaluated. If there was a depiction of bodily injury, the degree of damage to the body was rated as mild (bruises, lacerations, broken bones); severe (maiming, blinding, disfigurement); or critical (fatal wounds). Bodily consequences could be shown without depiction of the violent act. Medical treatment after the injury was scored as present or absent; any attempt by any other character in the film to attend to the victim was included. Each violent action was evaluated as either intentional on the part of the person or persons who initiated the action, or unintentional (as in the case of "acts of nature" or apparent "accidents").

Logistic regression analyses were used to determine patterns of seriousness, explicitness, and intentionality of violent actions as well as

Table 1 Number, mean, minimum, and maximum number of violent actions per film, by genre

\begin{tabular}{lclcc}
\hline Genre & $\begin{array}{l}\text { No of violent } \\
\text { actions }\end{array}$ & Mean/film & Minimum & Maximum \\
\hline Action $(\mathrm{n}=14)$ & 658 & 47.0 & 13 & 110 \\
Comedy $(\mathrm{n}=41)$ & 586 & 14.3 & 1 & 81 \\
Drama $(\mathrm{n}=26)$ & 437 & 16.8 & 0 & 44 \\
Other $(\mathrm{n}=19)$ & 503 & 26.5 & 1 & 97 \\
Total $(\mathrm{n}=100)$ & 2184 & 21.8 & 0 & 110 \\
\hline
\end{tabular}

injury severity and consequences from injury. To quantify the deviance of each genre from the overall pattern of violent actions with regard to each characteristic, logistic regression models were run to compare films within each genre with all other genres. For purposes of analysis, the three genres of action, comedy and drama (which comprised 81 films in the sample) were considered as unique groups; films in the remaining genres were aggregated.

\section{Results}

A total of 2184 violent actions against people were identified in the sample (table 1). This corresponds to one violent action approximately every five minutes; every film in the study sample except one (Quiz Show, Hollywood Pictures) contained at least one violent action. The largest number of such actions in a single film was 110 (recorded in the action film Timecop, MCA/Universal Pictures). One of the family films (Lion King, Walt Disney Productions) had nearly as many-97 separate violent actions.

The data show that $963(44.1 \%)$ violent actions used lethal force, $817(37.4 \%)$ used moderate force, and $404(18.5 \%)$ used only minimal force. Lethal force was most frequent in the action genre, in which $56.8 \%$ of all violent actions were rated lethal. Explicitness was rated either none or minimal in 1932 scenes $(88.4 \%)$ but moderate in $222(10.2 \%)$ and maximum in $30(1.4 \%)$. Included in this last category were scenes from seven of the 14 action films.

Violence was 10 times more frequently the result of intentional rather than unintentional acts, with 1991 intentional and 193 unintentional violent actions identified in the entire sample. Intentional violent actions showed an absence of injury consequences more often than unintentional, with $87.0 \%$ of intentional and $75.6 \%$ of unintentional actions depicting neither bodily nor medical consequences.

At least one action with the highest level of injury severity was identified at least once in 13 of the 14 action films, in nine of the 41 comedies, in eight of the 26 dramas, and in nine of the remaining 19 films. Across all films in the sample, a total of $1897(86.9 \%)$ violent actions showed no consequent bodily injury or medical attention, while only 254 showed bodily injury (11.6\%), 16 showed medical attention $(0.7 \%)$, and 17 showed both bodily injury and medical attention $(0.8 \%)$ (table 2$)$. The presence of bodily consequences was found most frequently in actions using lethal force (71.8\%). Actions not depicting injury consequences were more equally distributed by seriousness, with $39.9 \%$ of lethal actions, $39.3 \%$ of moderate actions, and $20.8 \%$ of minimal actions showing no injury consequences.

In nine of every 10 violent scenes, the injury to the victim was not depicted (table 3 ). When consequences to bodies were shown, however, $118(54.1 \%)$ were critical (for example, dead or dying persons), 55 (25.2\%) were severe (for example, broken bones, severe blood loss), and 
Table 2 Number (\%) of violent actions without consequences, with bodily injury, and/or with medical attention, by film genre

\begin{tabular}{lccccc}
\hline Genre & No consequences & $\begin{array}{l}\text { Bodily } \\
\text { injury only }\end{array}$ & $\begin{array}{l}\text { Medical } \\
\text { attention only }\end{array}$ & $\begin{array}{l}\text { Bodily injury } \\
\text { and medical } \\
\text { attention }\end{array}$ & $\begin{array}{l}\text { No of total } \\
\text { violent actions }\end{array}$ \\
\hline Action & $594(27.2)$ & $57(2.6)$ & $4(0.2)$ & $3(0.1)$ & 658 \\
Comedy & $496(22.7)$ & $83(3.8)$ & $6(0.3)$ & $1(0.0)$ & 586 \\
Drama & $375(17.2)$ & $49(2.2)$ & $4(0.2)$ & $9(0.4)$ & 437 \\
Other & $432(19.8)$ & $65(3.0)$ & $2(0.1)$ & $4(0.2)$ & 503 \\
Total & $1897(86.6)$ & $254(11.6)$ & $16(0.7)$ & $17(0.8)$ & 2184 \\
\hline
\end{tabular}

Table 3 Injury severity by seriousness of violent action; results are number (\%)

\begin{tabular}{lcrrrr}
\hline \multirow{5}{*}{ Seriousness } & \multicolumn{2}{l}{ Injury severity } & & & \\
\cline { 2 - 4 } & \multicolumn{1}{l}{ Mild } & \multicolumn{1}{c}{ Severe } & \multicolumn{1}{c}{ Critical } & Injury not shown & \multirow{2}{*}{ Total } \\
\hline Minimal & $1(0.0)$ & $1(0.0)$ & $2(0.1)$ & $400(18.3)$ & 404 \\
Moderate & $33(1.5$ & $14(0.6)$ & $1(0.0)$ & $769(35.2)$ & 817 \\
Lethal & $11(0.5)$ & $40(1.8)$ & $115(5.3)$ & $797(36.5)$ & 963 \\
Total & $45(2.1)$ & $55(2.5)$ & $118(5.4)$ & $1966(90.0)$ & 2184
\end{tabular}

$45(20.6 \%)$ were mild (for example, bruises, slight lacerations).

Two special types of scenes were identified in the analysis: the first of these included scenes in which violent actions of high lethality and their effects on the body of the recipient were both graphically portrayed. A total of 115 scenes, $5.3 \%$ of all scenes in which violence was present, fit this description. Such scenes were found in $13(92.9 \%)$ of the action movies, in nine $(22.0 \%)$ of the comedies, and in eight $(30.8 \%)$ of the dramas. In the action genre, one out of every twelve violent actions overall were of this type. Illustrations were found in 15 different scenes in Beverly Hills Cop 3 (Paramount Pictures), in nine different scenes in Stargate (Carolco Pictures), and at least once in 37 other films in the study sample.

The other special type was comprised of scenes depicting violence which would ordinarily result in massive injuries to the recipient but - in the world of film-did not. Such portrayals were found in 797 scenes, or $36.5 \%$ of all scenes in which violence was present. Up to 51 such scenes were found in a single action film (True Lies, Lightstorm), on average half of all the violent scenes in action movies. Scenes of this type occurred in $57.5 \%$ of the comedy films, with one comedy film ( A Low Down Dirty Shame, Hollywood Pictures) depicting such scenes 31 different times. In dramas this type of scene occurred in $65.2 \%$, with one dramatic film (Natural Born Killers, Warner Bros) containing 25 separate instances. All but three of the films in the remaining genres also included violence of high lethality but without injury; the average number of such scenes in those films was 9.7 per film.

Table 4 Odds ratios and 95\% confidence intervals for three principal genres by violence characteristic

\begin{tabular}{llll}
\hline \multirow{2}{*}{$\begin{array}{l}\text { Violence } \\
\text { characteristic }\end{array}$} & Genre & & \\
\cline { 2 - 4 } & Action & Comedy & Drama \\
\hline Seriousness & $1.24(1.08$ to 1.42$)$ & $0.80(0.69$ to 0.92$)$ & $0.84(0.71$ to 1.00$)$ \\
Explicitness & $1.46(1.26$ to 1.69$)$ & $0.56(0.47$ to 0.67$)$ & $1.42(1.19$ to 1.70$)$ \\
Injury severity & $0.84(0.70$ to 1.01$)$ & $1.18(0.98$ to 1.41$)$ & $0.89(0.73$ to 1.08$)$ \\
Consequences & $0.82(0.60$ to 1.13$)$ & $1.09(0.81$ to 1.46$)$ & $1.34(0.99$ to 1.83$)$ \\
Intentionality & $2.42(1.66$ to 3.54$)$ & $0.40(0.30$ to 0.55$)$ & $1.63(1.05$ to 2.52$)$ \\
\hline
\end{tabular}

Logistic regression analyses showed that action films had significantly more serious (odds ratio $(\mathrm{OR})=1.2$ ) and more explicit $(\mathrm{OR}$ $=1.5$ ) depictions of violence than other genres, and also exhibited a greater degree of intentionality $(\mathrm{OR}=2.4)$ (table 4$)$. However, in action films neither the resulting injury severities nor the number of consequences resulting from injuries were significantly greater or lesser than those in other genres $(\mathrm{OR}=0.84$ and 0.82 , respectively).

In contrast to action films, comedies had lower levels of seriousness $(\mathrm{OR}=0.80)$, lower levels of explicitness $(\mathrm{OR}=0.57)$, and the lowest degree of intentionality of all genres $(\mathrm{OR}=$ 0.41). Comedies had average levels of both injury severity and consequences from injuries. Films in the drama genre had higher levels of explicitness $(\mathrm{OR}=1.42)$ and higher levels of intentionality $(\mathrm{OR}=1.63)$ than films in other genres but lower levels of seriousness $(\mathrm{OR}=$ $0.84)$.

\section{Discussion}

Two highly consistent features were found in the depiction of violence in the 100 top grossing American films in 1994: first, film violence was most often an intentional act of one character towards another, and, second, consequences of violent events were most often omitted. While the majority of violent actions depicted moderate or lethal force, more than six out of every seven violent actions in the study sample contained no portrayal at all of consequences of those actions, either in terms of bodily injury or medical attention (an illustration is the gang beating of a ninja character in Three Ninjas Kick Back, Ben-Ami/ Leeds Productions). In the film world the human body's durability under violent attack is often greatly exaggerated, the links between injury causes and consequences appearing to have been suspended altogether. On the other hand, numerous scenes depicting violent acts raised the violence to maximum levels for both the initiator of the violence and the recipient (an illustration is the Vietnam war sequence in Forrest Gump, Paramount Pictures).

Relative to other films, action films had an increased severity of action coupled with reduced severity of injury and a general lack of consequences to recipients of those actions. The depictions of violence in the action genre tended to contain a discord between the often extreme severity of the action coupled with a lack of severity in its consequences. In contrast, although numerous, violent actions in comedies were less serious, less explicit, and less likely to be intentional. Dramas tended to depict less serious violent actions and lesser injury severities, but their violent actions tended to be more explicit and were more likely to be intentional.

This study is limited by several factors, including its sampling, its scoring methods, and its choice not to assess psychological or behavioral sequelae for viewers of the violent scenes. As the sample represents the most widely seen movies of the year 1994 and is 
characteristic of the American film industry at the end of the 20th century, generalizability is good. The scaling was intentionally simple, though it may have led to oversimplification of especially complex scenes. Psychological consequences for the film characters (initiator, recipient, bystander) involved in the violence were assessed during coding but not included in this paper. No attempt was made with these 100 films, however, to assess audience reactions. We also did not distinguish in judgmental terms between films with differing violent profiles.

Violence has always been a part of American movies, starting from the first film to be distributed widely (The Great Train Robbery) which contained an optional reel of gunplay left to the discretion of the local projectionist. Glucksman cited figures from the 1930s that found 45 murders and over 400 crimes in 115 separate crime films, and from the 1950s that identified over 650 crimes or acts of violence in 100 selected films from that era ${ }^{6}$ But for years the Hays Production Code kept the appearance of criminal violence, sex, vulgar language, and obscenity below a strict threshold. Since the code was retired in 1968, a much less stringently defined rating process under the aegis of the Motion Picture Association of America (MPAA) has been used. ${ }^{7}$ This voluntary system is often the sole hurdle outside the production company through which an American movie passes before entering the marketplace. Standards for presentation of violence in movies continue to evolve; a complex interlocking set of additional forces for change has also included the increasing number of entertainment outlets other than the movies, growing competition within the movie industry itself, and emphasis on international marketing (and attendant demands for less talk, more action).

Critics have commented that the use of extreme violence by many in the present generation of filmmakers means that, by repetition and overfamiliarity, violence no longer conveys the inherent meaning that it once did. It may be that violence is utilized to move the film's story forward with conflict and narrative structure in place of more difficult tasks involving development of story and character. Stephen Prince, a leading film critic, points out that:

"Graphic violence is now embedded in contemporary cinema as a formulaic element, endlessly repeated, and often removed from any recognizably human context. It solves story problems by providing talented as well as mediocre filmmakers with an easily-assembled, if mechanical, narrative structure. It also substitutes for thought and reflection". ${ }^{8}$

However, central to issues of art, style, and storytelling is the possibility that violence serves as an opportunity for the filmmaker, as noted by Lewis Cole, chair of the Film Division of Columbia University's School of the Arts:

"The moment when rationality fails and a character throws him-or herself into action is a crucial option for a dramatist. The realistic portrayal of violence is one of the distinguishing marks of great artists...". 9
The results of this study suggest three separate considerations. The first is that, through the appearance of violence against persons across all film genres, a message is being sent that such violence deserves to be watched. The huge gross from violent films shows that consumers around the globe support this notion. To meet public demand for their product, screenwriters and filmmakers continue making movies that portray violent actions.

The second consideration is that high levels of violence, whether intentional or unintentional, over time seem to become acceptableperhaps even expected by the modern viewing audience. (Violent scenes in films from earlier eras now often appear as if they "...wore the soft gloves of much gentler conventions... ${ }^{10}$; future generations may even say the same about violence in today's films.) Viewers of contemporary movies may indeed recognize that a given violent act against another human would not necessarily occur in the way it is shown on film. The professional specialities of stunt double, fight choreographer, and special effects coordinator are dedicated, however, to convincing movie audiences to believe otherwise.

The third consideration addresses public health and injury prevention education in particular: through de-emphasis of injury consequences in the movies, many times the intentionally violent actions by one person against another appear to have no injurious outcomes. Once over a certain threshold, however, when the violent action is exaggerated to a high degree, the consequences to the recipient of that action are shown as lethal. This dichotomy depicts only fragments of the relationship between violent actions and consequent injuries, and may become problematic if it succeeds in misleading viewers about the nature and extent of injuries that might accompany performance of all but the most violent of violent acts.

Public health will probably not be advanced by attempting to convince the film industry to soften the appearance or diminish the intensity of movie scenes that include violence against persons. But, paralleling the efforts to persuade moviemakers to reduce the number of actors shown smoking cigarettes and increase the visibility of seat belt use, it may be time for the public health community to express its opinion about the use of violence against persons with misleading portrayals of injury consequences.

Support for this research was provided by the Southern California Injury Prevention Research Center, which is funded by a rant from the Centers for Disease Control and Prevention \#CCR 903622).

Portions of this paper were presented at the Fifth World Conference on Injury Prevention and Control, New Delhi, India, 5-8 March 2000.

1 National Television Violence Study. Scientific papers 19941995. Studio City, CA: Mediascope Inc, 1996 (I-133-I1995.

2 Mediascope; University of California, Santa Barbara; University of North Carolina, Chapel Hill; University of Texas, Austin; University of Wisconsin, Madison. National Texas, Austin; University of Wisconsin, Madison. National
television violence study, 1998. Thousand Oaks, CA, Sage television violence study

3 Cole J. National Television Violence Monitoring Project. The UCLA television violence report 1997. Los Angeles, CA: UCLA Center for Communications Policy, 1998. 
4 Committee on Communications. Media violence, policy statement, American Academy of Pediatrics. Pediatric 1995;95:949-51.

5 Murphy AD. 1994 Film industry results; independent producers and distributors special issue. The Hollywood Reporter, 1995.

6 Glucksmann A. Violence on the screen. (Translated by S Bennett.) London: British Film Institute Education Department, 1971.

7 Wallace A. MPAA's dozen judge movies for millions. Los Angeles Times 18 July 1999: A1, A32-3.

8 Prince S. Savage cinema: Sam Peckinpah and the rise of ultraviolent movies. Austin, TX: University of Texas Press, 1998

9 Cole L. Violence and the media: the wrong controversy? 21st C: the World of Research. New York: Columbia University, 1.2, Fall 1995: 11 .

10 Amis M. Blown away. In: French K, ed. Screen violence. London: Bloomsbury, 1996.

\section{Appendix A}

Film titles included in study sample (alphabetical order):

A Low Down Dirty Shame, Above the Rim, Ace Ventura, Andre, Angels in the Outfield, Baby's Day Out, Bad Girls, Beverly Hills Cop 3, Blank Check, Blink, Blown Away, Blue Chips, Bullets Over Broadway, City Slickers 2, Clear and Present Danger, Corrina, Corrina, Crooklyn, D2 The Mighty Ducks, Disclosure, Drop
Zone, Dumb and Dumber, 8 seconds, Forrest Gump, Four Weddings and a Funeral, Getting Even With Dad, Greedy, Guarding Tess, House Party 3, I Love Trouble, IQ, In the Army Now, Intersection, Interview with a Vampire, Iron Will, It Could Happen to You, Jason's Lyric, Junior, Legends of the Fall, Lightning Jack, Little Big League, Little Giants, Little Women, Love Affair, Major League 2, Mary Shelley's Frankenstein, Maverick, Milk Money, Miracle on 34th Street, Monkey Trouble, My Father The Hero, My Girl 2, Naked Gun 331/3, Natural Born Killers, Nell, No Escape, Nobody's Fool, On Deadly Ground, Only You, Pulp Fiction, Quiz Show, Reality Bites, Renaissance Man, Richie Rich, Speechless, Speed, Star Trek Generations, Stargate, Street Fighter, Sugar Hill, Terminal Velocity, The River Wild, The Santa Clause, The Paper, The Professional, The Pagemaster, The War, The Specialist, The Shawshank Redemption, The Shadow, The Little Rascals, The Cowboy Way, The Client, The Mask, The Air Up There, The Color of Night, The Crow, The Getaway, The Lion King, The Madness of King George, The Jungle Book, The Flintstones, Three Ninjas Kick Back, Threesome, Timecop, True Lies, Wes Craven's New Nightmare, When A Man Loves A Woman, With Honors, Wolf, Wyatt Earp.

\section{Motorists benefit from improved safety standards but pedestrians suffer}

The safety standards of Britain's smallest cars have improved dramatically, but they still pose an unacceptably high risk to pedestrians, according to European research. The cars have been given higher marks for occupant protection by safety experts than when similar tests were carried out on new models three years ago, when the small cars were found to offer poor protection. Small cars similar to those tested are driven by almost half of 17-24 year olds, who are the drivers most likely to be involved in an accident. However, although all cars sold in Britain received high ratings for occupant protection, the tests examine only the effects of hitting a stationary object or a similar vehicle. Safety campaigners remain worried about the dangers to occupants of small cars that are involved in collisions with larger vehicles.

Even on occupant safety, work still needed to be done, a spokesperson for the European New Car Assessment Programme (EuroNCAP) said. The tests showed a continuing risk of chest injuries from impact forces transmitted by seat belts. Restraints did not always protect children from head and neck injury as well as they should, while testers found too many instances where the risks of putting a child in a rear-facing restraint opposite an airbag were poorly explained.

A further concern is pedestrian safety. EuroNCAP said: "No car tested did much to lessen injury should it strike somebody". In this area, each of the seven models in the latest test received a two star rating, which was at least an improvement on the 1997 result when five of the seven cars got only one star. The issue is to be addressed.

European car manufacturers will next month adopt a programme of improved car designs to protect pedestrians, including more rounded car fronts, and providing more space between engine casings and bonnets (The Times (London), 25 February 2000). 